\title{
CERVANTES Y SU POSTURA ANTE LA LENGUA
}

José Luis Galván

Docente Universidad Politécnica Salesiana

En un momento de malhumor, Don Quijote prohíbe a Sancho departir con él. Sin embargo, este "áspero mandamiento del silencio" debe ser levantado porque tanto Don Quijote como su escudero no son capaces de seguir callados, y la novela no puede condenarse al mutismo. Desde entonces los personajes se verán arrojados en la lengua, y ésta marcará el horizonte que envuelve sus vidas. El lector de hoy, inexorablemente, debe sumergirse en esta lengua si pretende comprender y gozar de las creaciones cervantinas.

Son muchos los personajes de la novela que en su modo de hablar quedan individualizados: el galeote Ginés de Pasamonte y su jerga rufianesca; el canónigo, discreto y conocedor de materias literarias; el vizcaíno con su lengua castellana estropeada; Sancho y sus prevaricaciones cuando usa alguna palabra culta y es corregido por Don Quijote que cuida de su buen uso, sin un afán de erudición, como se podría pensar, sino queriendo él mismo oponer el habla popular del criado al discurso culto y literario del amo. 
El Quijote de la Mancha pone de manifiesto su actitud ante la lengua: por un lado el escritor culto y elegante y por otro el escritor capaz de reproducir el estilo coloquial del pueblo. Esta actitud culta y tradicional propia de la prosa castellana procura atenerse a la fórmula que el mismo Cervantes se dicta en el prólogo: escribir "a la llana, con palabras significantes, honestas y bien colocadas, salga vuestra oración y periodo sonoro y festivo, pintado, en todo lo que alcanzáredes y fuere posible, vuestra intención; dando a entender vuestros conceptos sin intrincarlos ni oscurecerlos".

Para el joven lector de hoy, Don Quijote y Sancho tienen una existencia anterior al texto mismo. Es decir, todos hemos escuchado hablar de esta pareja literaria, de alguna de sus aventuras, de su carácter, de sus actuaciones proverbiales. Sin embargo, ya metido en la lectura, descubrirá que ese mundo es ajeno al suyo, que esas experiencias cotidianas le pueden parecer artificiosas y poco convencionales. Entonces se le plantean dos alternativas: la más simple, abandonar la novela; la más rica, atreverse por esos caminos, quizá no como erudito, pero sí como lector provisto de cierta formación histórica y literaria que le permita degustar con placer esta historia sin par. El objetivo de este trabajo es, por ello, acercar al posible lector del Quijote a esta doble aventura: la de la lengua literaria y la de la vida de don Quijote y Sancho.

\section{Breve nota sobre Cervantes}

Miguel de Cervantes Saavedra, hijo de Rodrigo de Cervantes y de Leonor de Cortinas, probablemente nació el 29 de septiembre de 1547, día de San Miguel. Su padre, modesto cirujano, tuvo siete hijos; Miguel fue el cuarto. Poco se sabe de sus primeros estudios. Es seguro 
que no llegaron a ser universitarios. Es probable que estudiase en la Compañía de Jesús, por la evocación que se hace en su novela El coloquio de los perros.

En 1569 está en Roma, fugitivo de España, por haber causado heridas a Antonio de Sigura. En 1570 ingresa como soldado. Y en 1571 se halla en la acción de Lepanto. De donde salió estropeado en su mano izquierda, que no le fue cortada, pero sí le quedó anquilosada. La herida, al parecer, no fue muy grave, pues participó en otras batallas.

En 1575 son hechos prisioneros Miguel y su hermano Rodrigo por los turcos. Las cartas de recomendación de don Juan de Austria, que llevaba Cervantes, hicieron pensar que era gran personaje y del cual se podría conseguir gran botín. Cinco años de cautiverio en Argel hicieron de Cervantes un hombre de espíritu fuerte. En cuatro ocasiones intentó la fuga, y en todas falló. Aun así, jamás delató a sus amigos y prefirió la tortura. Su madre intentaba por todos los medios reunir el dinero para su rescate (500 ducados), pero jamás consiguió tal suma. Sólo en 1580 los padres trinitarios lograron, angustiosamente, recolectar la suma entre los mercaderes cristianos y salvar a Cervantes de penas mayores.

En 1582 solicita un empleo que estaba vacante en Las Indias, pero su petición es negada. Por esta época tiene una hija con Ana Villafranca de Rojas, a la que llamaron Isabel de Saavedra. En 1584 se casó con Catalina de Salazar y Palacios, joven mujer de 20 años.

Entre 1581 y 1583 aparece su primera obra importante, $\mathrm{La}$ Galatea, pues hasta entonces sólo era un aficionado a la poesía.

Entre 1587 y 1600 Cervantes se halla en la ingrata tarea de requisar cereales y aceite por toda Andalucía. Este oficio le fue encargado para proveer de abastos a las 
galeras reales que Felipe II proyectaba enviar contra Inglaterra.

En 1590 vuelve a insistir por un empleo en las Indias. Afortunadamente le fue negado por segunda vez, pues de otra manera, si lograba llegar a América, no habría conseguido escribir su genial novela.

En 1592 es encarcelado por vender fanegas de trigo sin autorización, y en 1597 nuevamente está en la cárcel, pues había depositado lo recaudado en alcabalas y otros impuestos en una casa de banca que luego quebraría. De ahí la referencia de Cervantes cuando dice que $E l$ Quijote fue engendrado en una cárcel ${ }^{1}$.

En septiembre de 1604 obtiene la anuencia real para publicar El Quijote. Pero el mismo año es encarcelado por mala fe. El caballero Gaspar de Ezpeleta es herido mortalmente frente a su casa; Cervantes acude en su ayuda, y es implicado en dicha reyerta.

Habían pasado 20 años, desde que en 1585 publicó La Galatea, hasta la aparición de El Quijote. El éxito de esta obra hizo de Cervantes un escritor prolífico. En 1613 aparecen las Novelas ejemplares; en 1614 el Viaje del Parnaso; en 1615 la Segunda parte de El Quijote y Comedias y entremeces; y en 1617, póstumamente, Persiles y Sigismunda. En términos generales se trata de un escritor viejo: entre los 66 y 68 años, que es cuando produce la mayor parte de su obra.

El 22 de abril de 1616 muere Miguel de Cervantes en Madrid. Tres días antes redacta su dedicatoria al conde de Lemos en su obra Los trabajos de Persiles y Segismunda:

Aquellas coplas antiguas, que fueron en su tiempo celebradas, que comienzan: 
Puesto ya el pie en el estribo, quisiera yo no vinieran tan a pelo en esta mi epístola, porque casi con las mismas palabras las puedo comenzar, diciendo:

Puesto ya el pie en el estribo, con las ansias de la muerte, gran señor, ésta te escribo.

\section{El devenir de la lengua}

La lengua interpreta y traduce la realidad, pero al mismo tiempo es una creación metafórica de ella. En la Edad Media se concebía la lengua como instrumento para conocer y catalogar el mundo. La palabra era la cosa misma, había correspondencia entre la palabra y la realidad. El Renacimiento se interna en el espíritu del hombre a través de la lengua, la lengua traduce sentimientos; de ahí su interés por el lenguaje del pueblo, pues este expresa mejor la filosofía y el espíritu de un pueblo. De este espíritu renacentista nacerá la Gramática de Nebrija; lo mismo Canciones y dezires (1449) del Marqués de Santillana. Igualmente ocurre con Diálogo de la lengua (1535) de Juan de Valdés: las palabras son la savia del ser de un pueblo, de una raza. El ejemplo es notable en Cervantes con el caudal de refranes de Sancho frente al lenguaje, al principio culto, de Don Quijote.

En el siglo XI, el castellano, dialecto rudo de aldeanos y soldados, alejado del viejo latín de los conquistadores, empieza a tener vida literaria. Pero sólo en el siglo XV, en 1492, Nebrija procurará ennoblecerlo; según él ya no se podía esperar que esta lengua "subiera", y sólo se podía esperar su "descendimiento", y para ello escribió su Gramática Castellana. 
El siglo XVI es el que más se plantea el problema de la lengua: Garcilaso y su afán de vestir sus versos con los adornos de la poesía italiana. Fray Luis de León y su consejo de elegir las palabras más convenientes, armónicas y dulces y poner medida en la prosa. Fernando de Herrera va más allá: hay que vestir a la lengua con pompa y majestad. Góngora y su lengua poética para escogidos e iniciados. Pero también está el viejo ideal de la naturalidad: La Celestina, El Lazarillo de Tormes, Lope de Vega.

Es en El Quijote donde Cervantes esbozó mejor su ideal de la lengua. Ésta se manifiesta, ante las dos vertientes anteriores, en una crítica de la afectación cultista y una crítica de las prevaricaciones del habla vulgar.

\section{Juan de Valdés}

El siglo XVI es el de la edad del esplendor de la lengua castellana. Es la época en que, con Carlos I (15171556), se produce la apertura del imperio; culturalmente aparece el erasmismo y su intento de zanjar la crisis religiosa e ideológica de la época mediante el diálogo; y económicamente, se vive una época de general prosperidad. Más que Fernando III, Alfonso X y los Reyes Católicos y sus aportes para la unificación y extensión del castellano, es Carlos I quien logró hacer del castellano una lengua universal. A pesar de que hasta los dieciocho años aún no hablaba español (cuando llega a España se vale de intérpretes) sorprende a todos cuando ante el senado genovés habla en castellano: "Aunque pudiera hablaros en latín, toscano, francés y tudesco, he querido preferir la lengua castellana porque me entiendan todos«» (Juan de Valdés, Diálogo de la lengua, en estudio introductorio, p. 17).

Esta situación parece propicia para buscar un sentido de perfección que aún no se había conseguido en 
la literatura. Hasta entonces la lengua distaba de lo que se entendía entonces como buen gusto; es decir, la expresión natural y normal, no sólo en la literatura, sino en toda la vida. Este buen gusto lo va a imponer el humanismo. Este objetivo de perfección iba a ser perseguido por Valdés, con su Diálogo de la lengua, Garcilaso con su poesía y Boscán con el dominio de la prosa.

Tal naturalidad, que debe emanar de la naturaleza cuyo centro es el hombre, debe ser buscada en las palabras y expresiones del lenguaje vulgar y natural del diálogo y ensartarlo en la lengua del arte. Pero no todo el lenguaje vulgar puede pasar al arte; hay que hacer una selección, escogiendo lo mejor de la lengua hablada.

Elementos vulgares eran, por ejemplo, los refranes, que ya gozaban de una larga tradición. Ellos son la esencia de la sabiduría popular, de la belleza natural en la forma de expresión, y son 'españoles'. Diferentes a los refranes griegos y latinos - nacidos entre personas cultas y doctas y celebrados en libros de gran filosofía- los refranes castellanos son tomados y nacidos del vulgo. El refrán se caracteriza por su concisión, de ahí que Valdés señalara: "Todo el bien hablar castellano consiste en que digáis lo que queréis con las menos palabras que pudiéredes". Don Quijote se refiere a ellos así: "Paréceme Sancho, que no hay refrán que no sea verdadero, porque todos son sentencias sacadas de la misma experiencia, madre de las ciencias todas, especialmente aquel que dice: 'Donde una puerta se cierra, otra se abre"' (I, Cap. XXI, p. 188). Son conocidos los más de doscientos refranes que usa Cervantes a través de Sancho y de los cuales Don Quijote le reclama a su escudero por considerarlos excesivos. Cervantes parece poner en práctica lo dicho por Valdés, pues caracteriza a Sancho a través de una avalancha de refranes $^{3}$. 
Llama la atención, sin embargo, que Valdés aprobara el uso, en el lenguaje artístico, de lo artificioso, inventado, incluso del neologismo, seleccionado, claro está, con buen juicio. De ahí la presencia del latinismo y del helenismo. Esto se entendería por el desarrollo en este siglo de las humanidades clásicas. Sin embargo, la introducción de estos términos es siempre para dar nombre a nuevas ideas y no por la simple novedad verbal. Valdés introducirá, entonces, paradoja, tiranizar, idiota, ambición, dócil, superstición, decoro, palabras que aún se conservan. Además, Valdés, en su afán de crear una nueva lengua propone que se diga 'exército' y no 'hueste,' 'fatiga' y no 'cuita', 'placer y regocijo' y no 'solaz', 'centinela' y no 'escucha,' 'preguntar' y no 'pescudar,' 'fácil' y no 'raez'.

Para Valdés no existía diferencia entre la lengua escrita y la lengua hablada. Valdés quiere ser en el estilo natural y sin afectación: "el estilo que tengo me es natural, y sin afectación ninguna escrivo (sic) como hablo; solamente tengo cuidado de usar de vocablos que signifiquen bien lo que quiero decir, y dígolo quanto más llanamente me es posible, porque a mi parecer en ninguna lengua stá bien el afetación" (Diálogo..., p. 36). Lo mismo hace Cervantes cuando en El Quijote, Maese Pedro dice a su trujumán que relata la historia de Don Gaiferos y Melisendra: "Llaneza, muchacho; no encumbres: que toda afectación es mala" (II, 224).

Juan de Valdés en el Diálogo de la lengua (1535) es claro cuando dice que las palabras son la savia de la raza. Precisamente, Elena Percas hace notar que, a propósito de El Quijote, según Valdés, los refranes "son tomados de dichos vulgares". Valdés señala, también, que la importancia de los refranes para la conservación de la propiedad de la lengua está en su nacimiento en el vulgo, por la sabiduría y el provecho didáctico que ofrecen. Imposible olvidar a Sancho: su inocencia y sabiduría que se entrecruzan 
y confunden en su manera de hablar, en sus refranes. Valdés y Cervantes coincidirán, además, en el menosprecio por las "gramatiquerías» y la afectación. Valdés aconseja escribir sin afectación, al hablar y al escribir, teniendo cuidado de utilizar los vocablos que signifiquen lo que se quiere decir; por su parte, Cervantes dirá "Llaneza, muchacho, no te encumbres: que toda afectación es mala" (II, 224).

Es importante señalar, después de la lectura del Diálogo, la animadversión que sentía Valdés por Nebrija, a quien llama "Librixa". Valdés se apartará de Nebrija en tres aspectos:

1. Valdés no está de acuerdo con el intento de Nebrija por someter al castellano a reglas, pues la lengua vulgar no puede someterse ni reducirse a reglas. De ahí su declaración de no haber tenido necesidad de leer la Gramática de Nebrija.

2. Nebrija, según Valdés, parece poner en su Vocabulario sólo los vocablos españoles que tuvieran apoyo en los latinos o griegos. Es lógico que Nebrija pensara así: el español debía tener reglas como las tenían el latín y el griego.

3. Según Valdés, Nebrija no conocía bien la lengua castellana, pues era andaluz, y en este lugar la lengua "no está muy pura".

El objetivo del Diálogo, en todo caso, va a ser el de dotar a los amigos italianos de Valdés de una obra que ayudara al aprendizaje y perfeccionamiento del español, lengua importante en aquella sociedad. Por eso la comparación con muchas palabras italianas, el interés por dar a conocer el léxico usual frente al arcaico, el usado por la corte y el usado por el vulgo. 
No obstante, será Nebrija quien logrará romper la tradición de usar el latín como la única lengua culta. Sólo entonces la mayoría de países europeos sentirá la necesidad de demostrar la bondad de sus propias lenguas, llamadas vulgares, y de aceptar que son aptas para la expresión del arte, como lo fueron el latín y el griego.

\section{El castellano y el latín}

Era muy común en el siglo XVI someterse a la vieja tradición que imponía el exaltar la lengua latina y menospreciar la lengua vulgar. Pronta es la crítica y burla de Cervantes ante tal erudición latinizante. En el Coloquio de los perros, sus protagonistas, Cipión y Berganza, dialogan sobre los que disparan (o disparatan) con algunos latines por dárselas de grandes latinos, y de los que efectivamente lo saben:

Berganza: Hay algunos romancistas ${ }^{4}$ que en las conversaciones disparan de cuando en cuando con algún latín breve y compendioso, dando a entender a los que no lo entienden que son grandes latinos, $y$ apenas saben declinar un nombre ni conjugar un verbo.

Cipión: Por menor daño tengo ese que el que hacen los que verdaderamente saben latín, de los cuales hay algunos tan imprudentes que, hablando con un zapatero o con un sastre, arrojan latines como agua.

Berganza: Deso podremos inferir que tanto peca el que dice latines delante de quien los ignora, como el que los dice ignorándolos. 
Cipión: Pues otra cosa puedes advertir, y es que hay algunos que no les excusa el ser latinos de ser asnos. (...)

Berganza: Así es, porque también se puede decir una necedad en latín como en romance; y yo he visto letrados tontos y gramáticos pesados y romancistas vareteados ${ }^{5}$ con sus listas de latín, que con mucha facilidad pueden enfadar al mundo no una, sino muchas veces ${ }^{6}$.

De igual forma en El Quijote, en varias ocasiones, Cervantes se burla de la falsa erudición latinizante. En el prólogo, el autor duda de la valía de su novela: "sin juramento me podrás creer que quisiera que este libro, como hijo del entendimiento, fuera el más hermoso, el más gallardo y más discreto que pudiera imaginarse. Pero no he podido yo contravenir al orden de naturaleza, que en ella cada cosa engendra su semejante"7; su gracioso amigo, entonces, le aconseja intercalar sentencias o latines que supiera de memoria:

En lo de citar en las márgenes los libros y autores de donde sacáredes las sentencias y dichos que pusiéredes en vuestra historia, no hay más sino hacer de manera que venga a pelo algunas sentencias o latines que vos sepáis de memoria, o lo menos que os cuesten poco trabajo el buscalle, como será poner, tratando de libertad y cautiverio: Non bene pro toto libertas venditur auro ${ }^{7}$ (Prólogo, p. 11).

Y luego concluye: "con estos latínicos y otros tales os tendrán siquiera por gramático; que el serlo no es de poca honra y provecho el día de hoy" (Prólogo, p. 11). 
En uno de los poemas laudatorios de El Quijote, Urganda, la Desconocida, dice, en versos de cabo roto, del libro de Don Quijote:

$$
\begin{aligned}
& \text { Pues al cielo no le plu- } \\
& \text { que salieses tan ladi- } \\
& \text { como el negro Juan Lati-, } \\
& \text { hablar latines rehu- } 8
\end{aligned}
$$

En el capítulo XXII de la primera parte de $E l$ Quijote, un guarda se burla de uno de los galeotes, vestido con hábito de estudiante, cuando dice: "era muy grande hablador y muy gentil latino".

Sancho será quien, en muchas ocasiones, se encargue de arremeter con sus prevaricaciones idiomáticas. En el capítulo XXV, parte I, Sancho dice: "Quien ha infierno nula es retencio". Don Quijote aparenta no entenderle, y le explica: "Retencio es que quien está en el infierno, nunca sale dél, ni puede" (Quia in inferno nulla est redemptio). Asimismo son proverbiales los excesos verbales de Sancho. Para ponerles coto don Quijote trae a cuento el ejemplo de Gandalín, escudero de Amadís de Gaula (I, cap. XX), quien siempre hablaba a su señor con la gorra en la mano, inclinada la cabeza y doblado el cuerpo more turquesco. Le recuerda, además, que el escudero debe identificarse con los dolores del caballero: quando caput dolet..., etcétera (II. cap. II). Sancho le replica no entender otra lengua que la suya. Entonces don Quijote se lo traduce: "cuando la cabeza duele, todos los miembros duelen".

Cómicas son las intervenciones de don Quijote al dirigirse a Sancho. En una de ellas le reprocha su malhadada intervención ante el escuadrón del pueblo del rebuzno (II, cap. XXVIII): “dad gracias a Dios, Sancho, ya que os santiguaron con un palo, no os hicieran el per signum crucis con un alfanje" (una cuchillada en la cara). 
Asimismo, contundente es la burla a los cultistas que contiene la carta de Don Quijote a Sancho gobernador, a quien le advierte que peligra su amistad con los Duques (II, cap. LI): “- -Tengo de cumplir antes con mi profesión que con su gusto, conforme a lo que suele decirse: Amicus Plato sed magis amica veritas. Dígote este latín porque me doy a entender que después que eres gobernador lo habrás aprendido".

El mismo Erasmo de Rótterdam, en su Elogio de la locura (cap. VI, p. 101) se burla de los retóricos cuando dice:

Se ha visto, pues, que imito a los retóricos de nuestro tiempo, que se creen dioses si se muestran bilingües, como la sanguijuela, y tienen por cosa preclara introducir en su latín algunos pequeños vocablos griegos, con los que hacen a menudo un mosaico fuera de lugar. $Y$ en el caso de que ignoren estas lenguas, no tienen más que sacar de pergaminos apolillados cuatro o cinco palabrejas que suman al lector en las tinieblas, de manera que los que las comprendan les rindan por lo mismo mayor admiración.

Cervantes conocía el latín, pero no era un latinista. No era ni licenciado ni bachiller, pues a la edad que hubiera podido lograrlo quería ser soldado. Si bien respetó la erudición clásica, no estimaba la falsa erudición. No hay mayor alegato a favor de la lengua vulgar de España frente al latín que el que refiere don Quijote al Caballero del Verde Gabán (II, cap. XVI):

-A lo que decís, señor, que vuestro hijo no estima mucho la poesía de romance, doime a entender que no anda muy acertado en ello, y la razón es esta: el 
grande Homero no escribió en latín, porque era griego; ni Virgilio no escribió en griego, porque era latino. En resolución: todos los poetas antiguos escribieron en la lengua que mamaron en la leche, y no fueron a buscar en las extranjeras para declarar la alteza de sus conceptos; y siendo esto así, razón sería se extendiese esta costumbre por todas las naciones, y que no se desestimase el poeta alemán porque escribe en su lengua, ni el castellano, ni aun el vizcaíno, que escribe en la suya. Pero vuestro hijo (a lo que yo... imagino) no debe de estar mal con la poesía de romance, sino con los poetas que son meros romancistas, sin saber otras lenguas ni otras ciencias que adornen y despierten y ayuden a su natural impulso.

Será el humanismo el que convierta la lengua popular en lengua nacional, rescatando voces y sentires del pueblo que antes eran odiados.

\section{El Quijote}

El Quijote no es una sátira de la caballería o de los ideales caballerescos, del heroisismo y el idealismo como creyeron algunos románticos. El libro parodia un género literario muy común en el siglo XVI; se burla de unos libros que por sus exageraciones y falta de mesura ridiculizaban lo heroico y lo ideal de la caballería. El Quijote, en gran medida, es una crítica de la literatura de su tiempo y de la lengua literaria.

En el escrutinio de la biblioteca de don Quijote, por ejemplo, el Cura y el Barbero condenan a la hoguera al Amadís de Grecia de Feliciano de Silva, por las "endiabladas y revueltas razones de su autor": 
Ningunos le parecían tan bien como los que compuso el famoso Feliciano de Silva; porque la claridad de su prosa y aquellas entricadas razones suyas le parecían de perlas, y más cuando llegaba a leer aquellos requiebros y cartas de desafíos, donde en muchas partes hallaba escrito: "La razón de la sinrazón que a mi razón se hace, de tal manera mi razón enflaquece, que con razón me quejo de la vuestra hermosura". Y también cuando leía: «los altos cielos que de vuestra divinidad divinamente con las estrellas os fortifican, y os hacen merecedora del merecimiento que merece la vuestra grandeza». Con estas razones perdía el pobre caballero el juicio, y desvelábase por entenderlas y desentrañarles el sentido, que no se lo sacara ni las entendiera el mesmo Aristóteles, si resucitara para sólo ello (I. Cap. I, 29-30).

La afectación de los libros de caballería es objeto de crítica por parte de Cervantes. Don Quijote sale de su aldea una calurosa mañana de julio. Sin rumbo fijo, como los héroes de las novelas de caballería, habla consigo mismo en un lenguaje altisonante y lleno de arcaísmos, fantasea sobre lo que los futuros historiadores dirán de sus aventuras:

Apenas había el rubicundo Apolo tendido por la faz de la ancha y espaciosa tierra las doradas hebras de sus hermosos cabellos, y apenas los pequeños y pintados pajarillos con sus harpadas lenguas habían saludado con dulce y meliflua armonía la venida de la rosada Aurora, que, dejando la blanda cama del celoso marido, por la puertas y balcones del manchego horizonte a los mortales se mostraba, cuando el famoso caballero Don Quijote de la 
Mancha, dejando las ociosas plumas, subió sobre su famoso caballo Rocinante, y comenzó a caminar por el antiguo y conocido campo de Montiel (I. cap. II).

La crítica romántica encontraba en esta descripción del amanecer un "modelo de prosa". Ni Cervantes ni sus contemporáneos tomaron en serio este pasaje. El lector del siglo XVII, familiarizado con esta literatura y su 42 estilo, entendía inmediatamente la intención paródica de Cervantes. Es claro que él lo escribió con el afán de burlarse de las novelas de caballería y de parodiar su altisonante estilo. La prueba está en que en los libros de caballerías aparecen este tipo de descripciones pero escritas en serio. Además, Don Quijote, impregnado de esta prosa, la juzga admirable y, al mismo tiempo que la imita, Cervantes se burla de ella. Más adelante Cervantes comenta:

Con éstos iba ensartando otros disparates, todos al modo de los que sus libros le habían enseñado, imitando en cuanto podía su lenguaje; y con esto, caminaba tan despacio, y el sol entraba tan apriesa y con tanto ardor, que fuera bastante a derretirle los sesos, si algunos tuviera (I. Cap. I, p. 30).

Las cartas amatorias que Don Quijote envió a Dulcinea también fueron objeto de parodia. En esta, por ejemplo, se nota el uso de arcaísmos y exageraciones idílicas que hace Cervantes (I, cap. XXV, p. 245):

Soberana y alta señora:

El ferido de punta de ausencia y el llagado de las telas del corazón, dulcísima Dulcinea del Toboso, te envía la salud que él no tiene. Si tu fermosura me desprecia, 
si tu valor no es en mi pro, si tus desdenes son en mi afincamiento, maguer que yo sea asaz de sufrido, mal podré sostenerme en esta cuita, que, además de ser fuerte, es muy duradera. Mi buen escudero Sancho te dará entera relación, joh bella ingrata, amada enemiga mía!, del modo que por tu causa quedo: si gustares de acorrerme, tuyo soy; y si no, haz lo que te viniere en gusto, que con acabar mi vida habré satisfecho a tu crueldad y a mi deseo. Tuyo hasta la muerte,

El Caballero de la Triste Figura

En la parte II, cap. XXVI, Maese Pedro le recomienda al muchacho que mueve los títeres:

"—iLlaneza, muchacho; no te encumbres, que toda afectación es mala!”

Lo mismo hace Don Quijote cuando aconseja a Sancho, gobernador ya de la ínsula:

“-Anda despacio; habla con reposo; pero no de manera que parezca que te escuchas a ti mismo; que toda afectación es mala”.

La lucha contra la afectación es constante:

...una manera de contar breve, lisa, sin afectación ni afeites". "una manera de decir como natural, o como las cosas pasaron, desnudas y sin arreos (...) sin pinturas ni ornamentos de poetas o retóricos, guardando siempre un decoro propio (II, cap. I). El lenguaje puro, el propio, el elegante y claro, está en los discretos cortesanos (...): dije discretos, porque hay muchos que no lo son, y la discreción es la gramática del buen lenguaje, que se acompaña con el uso (II. cap. XIX). 


\section{Para leer el Quijote ${ }^{9}$}

El idioma ha cambiado y lo seguirá haciendo quizá con mayor vértigo que ayer y hoy. De aquí a un siglo, tal vez más pronto, se entenderá menos El Quijote, no se diga obras menos conocidas de los siglos XIV, XV, XVI o XVII. Es muy difícil que un lector contemporáneo no tenga que recurrir al diccionario de Autoridades, al de la Real Academia, a los estudios de especialistas cervantinos para entender y "leer bien" la obra inmortal. De ahí la importancia de analizar las voces, conjugaciones, cambios de género, número y más en la obra cervantina.

\section{Capítulo I}

En un lugar de la Mancha, de cuyo nombre no quiero acordarme...: Martín de Riquer señala que en la lengua de Cervantes el verbo "querer" a veces tiene un valor auxiliar, de manera que "no quiero acordarme" significa no me acuerdo". Lo mismo que cuando, después, se diga "quieren decir que tenía el nombre de Quijada", que viene a significar: "dicen que tenía el nombre de Quijada".

Rocín flaco: El caballo de mala traza y flaco. El caballo de trabajo, a distinción del que llaman de regalo. "Encontrar Sancho con su rocín": frase con que se explica que alguno halló otro semejante a él, o de su genio, o que le entendiese sus modales.

Una olla de algo más vaca que carnero, salpicón las más noches, duelos y quebrantos los sábados, lantejas los viernes...: Duelos y quebrantos: llaman en la Mancha a la tortilla de huevos y sesos.

Salpicón: fiambre de carne picada, compuesto y aderezado con pimienta, sal, vinagre y cebolla, todo mezclado. Hácese regularmente de vaca. 
Palomino: el pollo de la paloma. Regularmente se toma por el de la brava o campesina, porque el de la casera llaman pichón.

Sayo de velarte: especie de paño fino y estimado en lo antiguo.

Pantuflos: calzado sin orejas ni talón, que sirve para estar con conveniencia en casa.

Y los días de entresemana se honraba con su vellorí de lo más fino: Paño entrefino de color pardo ceniciento, o de lana sin teñir.

Tenía en su casa (...) y un mozo de campo y plaza que así ensillaba el rocín como tomaba la podadera: el criado que sirve en las casas en los ministerios de trabajo, aunque tenga mucha edad, porque regularmente se eligen mozos.

Dalle: forma arcaica del verbo dar. Dalle en lugar de darle. Es desconocido por ejemplo el do, del presente del indicativo, en lugar del doy.

Ingalaterra: epéntesis por Inglaterra.

Así para el aumento de su honra como para el servicio de su república: el gobierno del público. Se dice del gobierno de muchos, como distinto del gobierno monárquico. Por extensión se llaman también los pueblos.

Se dio priesa a poner en efecto lo que deseaba: la instancia, solicitud y presteza con que se ejecuta alguna cosa. Dar priessa: acometer con ímpetu, brío y resolución, obligando a huir al contrario.

Luengos siglos había que estaban puestas y olvidadas en un rincón: Lo mismo que largo.

Limpiolas y aderezolas lo mejor que pudo; pero vio que tenían una gran falta, y eran que no tenían celada de encaje, sino morrión simple; mas a esto suplió su industria: destreza o habilidad en cualquier arte. Es voz 
puramente latina. Se toma también para ingenio y sutileza, maña o artificio (Quevedo: "grandes gracias di a Dios viendo cuanto dio a los hombres en darles industria").

Y fue, a lo que se cree, que en un lugar cerca del suyo había una moza labradora de muy buen parecer, de quien él un tiempo anduvo enamorado, aunque, según se entiende, ella jamás lo supo ni le dio cata de ello: catar: ver, mirar, registrar. Cata: la prueba que se hace del vino y otros licores.

Rocinante: lo mismo que rocín. Dícese frecuentemente del que está muy flaco. (Quijote: "apenas han visto algún rocín flaco, cuando dicen allí va Rocinante").

\section{Capitulo II}

Subió sobre Rocinante, puesta su mal compuesta celada, embrazó su adarga, tomó su lanza...: Embrazar. tomar el escudo, pavés, adarga, rodela y entrarlo por sus asas en el brazo izquierdo, para defenderse y rebatir las puntas y golpes del contrario.

Le vino a la memoria que no era armado caballero y que, conforme a la ley de caballería, ni podía ni debía tomar armas con ningún caballero, y puesto que lo fuera, había de llevar armas blancas...: acción de prevenirse cada uno con lo que tiene y usa para estar pronto a pelear. El obsequio que se hace a las personas reales, a los generales y oficiales superiores cuando pasan por los cuerpos donde hay guardia. Velar las armas: es guardarlas, haciendo centinela cerca de ellas, sin perderlas de vista. Fue costumbre antigua, que cuando alguno era armado caballero las velaba y hacía como guardia para su custodia en alguna iglesia. Armas blancas: en el blazón se llamaban las que no tenían empresa en el escudo. Empressa: cierto símbolo o figura enigmática, con un mote breve y conci- 
so enderezado a manifestar lo que el ánimo quiere o pretende.

— iOh princesa Dulcinea, señora de este cautivo corazón! Mucho agravio me habedes fecho en despedirme y reprocharme con el riguroso afincamiento de mandarme no parecer ante la vuestra fermosura. Afincamiento: se suele tomar por pena y congoja mortal. Es voz anticuada.

Plégaos, señora, de membraros de este vuestro sujeto corazón...: lo mismo que acordarse.

Vio, no lejos del camino por donde iba, una venta...: La casa establecida en los caminos y despoblados para hospedage de los pasageros. Díjose así porque en ella se les vende lo que han menester.

Estaban acaso a la puerta dos mujeres mozas, de estas que llaman del partido...: las que son de mal vivir, vendiendo su cuerpo, que llaman comúnmente rameras.

-Non fuyan las vuestras mercedes, ni teman desaguisado alguno, $\mathrm{ca}$ a la orden de caballería que profeso non toca ni atañe facerle a ninguno... Ca: vale lo mismo que porque. Es voz del uso antiguo de la lengua. También se usó como relativo, y por lo mismo el qual o que. Non: partícula que vale lo mismo que no. Es voz anticuada.

Acuitedes. Acuitar. Cuita: aflicción y trabajo, necesidad con lamento y ansia.

Puesto que no quisiera descubrirme fasta que las fazañas fechas en vuestro servicio...

-Cualquiera yantaría yo —respondió don Quijote: lo mismo que comer. Es voz antigua. Se llamaba también cierto tributo que se pedía y cobraba de los pueblos, cuando el rey entraba en ellos, para la comida, que se le disponía, de donde tomó el nombre.

Majada: lugar o paraje donde se recoge de noche el ganado, y lo albergan los pastores. 
Pan candeal: el pan muy blanco y regalado. Se tiene por mejor preparado el que se hace de muy candeal harina. Panecillo que se hace de trigo candeal, y de un tamaño que pesa regularmente ocho onzas.

\section{Capitulo III}

Venteril: de venta

Segundara: del verbo segundar. Repetir un acto. Voz que casi no tiene uso en las porciones cultas. En zonas rurales es frecuente segundar, dar la segunda, para significar que se da por segunda vez la deshierba, la aporcadura, etcétera.

\section{Capitulo IV}

Cerca: vale por acerca: "Más viniéndole a la memoria los consejos de su huésped cerca de las prevenciones tan necesarias que había de llevar consigo..."

Pagalle: pagarle

Pagastes: pagaste.

Rompido: roto: “...que si él rompió el cuero de los zapatos que vos pagastes, vos le habéis rompido el de su cuerpo".

Vía: veía.

\section{Capitulo V}

Montiña: montaña

Volcar: revolcar

En hora maza: en mala hora.

Para mi santiguada: forma de juramento: "Para mi santiguada que yo los queme mañana antes que llegue la noche". 


\section{Capitulo VI}

Cuerpos de libros: volúmenes

Cala y cata: sin averiguar más: “...y todos los demás, sin hacer más cala y cata, perezcan”.

Ultramarino: largo plazo: “...y es menester quitarles todo aquello del castillo de la Fama y otras impertinencias de más importancia, para lo cual se les da término ultramarino".

\section{Palabras finales}

Sólo con el Renacimiento se va a intentar una dignificación de la lengua hablada, la vulgar, la de todos los días; entonces será considerada expresión misma del fondo misterioso de lo humano. El latín les parecerá a los renacentistas una lengua abstractamente internacional; la conciencia nacional habrá de buscar un punto de apoyo en las hablas locales.

Cervantes no es ajeno a esta disputa. Conoce de las posiciones de los latinistas y los renacentistas. Y tomará partido por estos últimos. A esto se suma la crítica que, de manera clara, hace Cervantes de la afectación, especialmente en Coloquio de los perros y en El Quijote.

Sin embargo, no será tan inocente Cervantes como para caer en un ingenuo naturalismo que, reconociendo la conveniencia y legitimidad de lo vulgar, dignifique por igual toda forma de expresión vulgar sólo por el hecho de serlo. Pues por este camino se va, y Cervantes lo sabe, a la negación o menoscabo de la cultura y el arte literario. De manera que, para el autor de El Quijote, en el idioma debe haber tanto naturaleza como arte. Dicho en boca de don Quijote (II, 19) se lee así: "El lenguaje puro, el propio, el elegante y claro está en los discretos cortesanos, aunque hayan nacido en Majalahonda; dije discretos 
porque hay muchos que no lo son, y la discreción es la gramática del buen lenguaje, que se acompaña con el uso". Es decir, la misma idea que tenemos en la actualidad: el lenguaje natural ha de ser decantado por la cultura y las llamadas buenas maneras. Sin olvidar que estas últimas no constituyen plena garantía, pues la cultura y el buen gusto bien pudieran ser hostiles a la creación literaria y a la vitalidad que toda lengua exige. Así lo cree Cervantes cuando Sancho se defiende: "Pues sabe que no me he criado en la corte, ni he estudiado en Salamanca para saber si añado o quito alguna letra a mis vocablos..., no hay para qué obligar al sayagués a que hable como el toledano, y toledanos puede haber que no las corten en el aire en esto del hablar polido".

La discreción, es decir el análisis racional, es para Cervantes lo que debe mandar a la hora de su uso. Pero sin caer en la inmovilidad del idioma. El poeta debe enriquecer la lengua y sacarla de aquellos ánimos estrechos y puritanos que quieren achicar la lengua, de suyo abundante y fértil y más cercana a lo popular y espontáneo que a lo tieso y agostado.

\section{Bibliografía}

\section{ALONSO, Amado}

1979 Castellano, español, idioma nacional. Buenos Aires: Losada.

CERVANTES, Miguel de

2005 Don Quijote de la Mancha. Madrid: Alfaguara.

CERVANTES, Miguel de

1995 Novelas Ejemplares. Madrid: Alianza.

ERASMO DE ROTERDAM

1981 Elogio de la locura. Barcelona: Bruguera.

PERCAS DE PONSETI, Elena

1975 Cervantes y su concepto del arte. Madrid: Gredos.

RIQUER, Martín de

1979 Aproximación al Quijote. Navarra: Salvat editores. 
RILEY, E. C.

2000 Introducción al "Quijote". Barcelona: Crítica.

VALDÉS, Juan de

1984 Diálogo de la lengua. Barcelona: Plaza \& Janés.

\section{Notas}

1 "Y, así, ¿qué podía engendrar el estéril y mal cultivado ingenio mío, sino la historia de un hijo seco, avellanado, antojadizo y lleno de pensamientos varios y nunca imaginados de otro alguno, bien como quien se engendró en una cárcel, donde toda incomodidad tiene su asiento y donde todo triste ruido hace su habitación?, en Prólogo, Don Quijote de la Mancha, p. 7.

2 Es importante observar que en la primera salida de don Quijote (son tres las salidas), que va hasta el capítulo VI, Cervantes se ve obligado a hacerle hablar a su personaje mediante largos soliloquios. Sólo cuando sale por segunda vez de su casa lo hará acompañado de Sancho: "solicitó don Quijote a un labrador vecino suyo, hombre de bien -si es que este título se puede dar al que es pobre-, pero de muy poca sal en la mollera" (Cap. VII, p. 72). Sin embargo, Sancho irá evolucionando y se contagiará del ingenio de su amo, y hasta se contagiará de su locura.

3 En el capítulo XIX de la parte I, se abre la vena refranera de Sancho: "El jumento está como conviene; la montaña, cerca; la hambre carga: no hay que hacer sino retirarnos con gentil compás de pies, $\mathrm{y}$, como dicen, váyase el muerto a la sepultura y el vivo a la hogaza” (p. 173). Y en el capítulo XXV se da el completo desborde: "Allá se lo hayan, con su pan se lo coman: si fueron amancebados o no, a Dios habrán dado la cuenta. De mis viñas vengo, no sé nada, no soy amigo de saber vidas ajenas, que el que compra y miente, en su bolsa lo siente. Cuanto más, que desnudo nací, desnudo me hallo: ni pierdo ni gano. Mas que lo fuesen, ¿qué me va a mí? Y muchos piensan que hay tocinos, y no hay estacas" (p. 233).

4 Es decir, el que no sabe más que romance, la lengua vulgar; el castellano.

5 El que mezcla romance y latín en su habla.

6 Miguel de Cervantes, Coloquio de los perros, p. 52.

7 La libertad no se vende bien ni por todo el oro del mundo.

8 Es decir, si al cielo no le plugo hacer a Cervantes tan gran latinista como lo fue el negro Juan Latino, debe renunciar al latín y hablar castellano. 
9 Se han escogido los seis primeros capítulos de la primera parte por corresponder éstos a la primera salida del Quijote. Las palabras que se anotan a continuación han sido consultadas del Diccionario de Autoridades, Madrid, Gredos, 1981. 